\title{
Comparative Study of The Influence of DehydroepiandrosteroneVersus Growth Hormone on The Improvement of Ovarian Reserve Markers in Women With Diminished Ovarian Reserve
}

\author{
Huda M. Beder ${ }^{1, ~ *}$ MSc, Ismail Talaat Al-Garhai ${ }^{2}$ MD, Salah Ahmed Al-Baltagi ${ }^{3}$ MD and \\ Yahia Abd El-Salam Wafa ${ }^{2}$ MD
}

*Corresponding Author:

Huda M. Beder

mohd_yazed75@yahoo.com

Received for publication Aprils, 2020; Accepted June19, 2020; Published onlineJune20, 2020.

Copyright 2020 The Authors published by Al-Azhar University, Faculty of Medicine, Cairo, Egypt. All rights reserved. This an openaccess article distributed under the legal terms, where it is permissible to download and share the work provided it is properly cited. The work cannot be changed in anyway or used commercially.

doi:10.21608/aimj.2020.27445.1193

${ }^{1}$ Obstetrics

and

GynecologyDepartment, $\mathrm{Al}$ Menshawi General Hospital, Tanta.

${ }^{2}$ Obstetrics

and

GynecologyDepartment, Faculty of Medicine, Al-Azhar University Cairo, Egypt.

${ }^{3}$ Clinical pathology Department, Faculty of Medicine, Al-Azhar University Cairo, Egypt.

\begin{abstract}
Background: The study aimed to evaluate the effects of dehydroepiandrosterone (DHEA) and growth hormone (GH) supplementation on the improvement of the ovarian reserve markers in women with history of POR in the previous In vitro fertilization (IVF) cycles.

Aim of the work:To evaluate the effects of DHEA and GH supplementation on the improvement of the ovarian reserve markers in women with history of POR in the previous In vitro fertilization (IVF) cycles.

Patients and methods: 90 adult female with POR were randomly allocated into 3 groups; each group included 30 patients. Control group received $\mathrm{HMG} / \mathrm{GnRH}$ antagonist protocol. GH group received $\mathrm{GH} / \mathrm{HMG} / \mathrm{GnRH}$ antagonist protocol. Patients received daily subcutaneous injection of $2.5 \mathrm{mg}$ of GH from day 21 of previous cycle, until the day of HCG injection. DHEA group received DHEA/HMG/GnRH antagonist protocol. Patients received $25 \mathrm{mg}$ of micronized DHEA, administered orally three times a day, for 12 weeks before starting the cycle of ovulation induction. The number of retrieved oocytes, fertilized oocytes, and embryos transferred, chemical pregnancy rate, the clinical pregnancy rate and LBR were recorded.

Results: The mean values of the number of the oocytes retrieved, the fertilized oocytes, the transferred embryo, the chemical pregnancy rate, clinical pregnancy rate, ongoing pregnancy rate and live birth rate (LBR) were statistically significant higher in the DHEA group compared to the control and the GH groups $(\mathrm{P}<0.05)$. While, there was no significant difference between the control group and the GH group $(\mathrm{P}>0.05)$.

Conclusion: The DHEA supplementation to the IVF protocol improved the number and quality of retrieved oocytes, the rate of clinical pregnancy and the LBR compared to the control group or the GH cotreatment to the IVF protocol.
\end{abstract}

Keywords: $\quad$ DHEA; IVF; Infertility Pregnancy rate.

Disclosure: The authors have no financial interest to
declare in relation to the content of this article. The
Article Processing Charge was paid for by the authors.
Authorship: All authors have a substantial contribution to the
article.

\section{INTRODUCTION}

The ovarian reserve reflects the woman's pregnancy chance; it differs between individuals and, at least partially, is under genetic control operated by Fragile $\mathrm{X}$ mental retardation 1 gene. ${ }^{1}$ Ovarian reserve defines both total ovarian reserve, a pool of growing follicles at different stages of maturation, and functional ovarian reserve, which is related to the size of the follicle pool and the follicle recruitment rate. ${ }^{2}$ The European Society of Human Reproduction and Embryology published the Bologna criteria in 2011 in order to standardize the definition of poor ovarian response (POR). ${ }^{3}$
Dehydroepiandrosterone (DHEA), an endogenous androgen, is produced in the zonareticularis of the adrenal gland and by ovarian theca cells, and converted to testosterone and estradiol (E2) in peripheral tissues. ${ }^{4}, 5$ The oral administration of DHEA before gonadotrophin stimulation to increase ovarian response in poor responder patients was proposed by. ${ }^{6}$

Growth hormone $(\mathrm{GH})$ regulates the effect of follicle-stimulating hormone (FSH) on granulose cells, by increasing the synthesis of Insulin-like growth factor 1 , augments the effect of gonadotropin on granulose and theca cells, and plays an essential role in ovarian function, including follicular 
development, estrogen synthesis and oocyte maturation. 7,8

This study aimed to evaluate the effects of DHEA and GH supplementation on the improvement of the ovarian reserve markers in women with history of POR in the previous In vitro fertilization (IVF) cycles. The primary outcomes of the study were the number of oocytes retrieved and the clinical pregnancy rate.

\section{PATIENTS AND METHODS}

After obtaining approval from the Institutional Ethics Committee and written informed consent from all the patients, 90 adult female with POR were included in this prospective randomized controlled trial (RCT). They were divided into 3 groups; each group included 30 patients. This study was conducted in Private Based IVF Units. All the data of patients were confidential with secret codes and private file for each patient, all given data were used for the current medical research only. Couples were counseled about the treatment protocols.

Inclusion criteria: Adult females with POR defined according to the Bolonga criteria $^{9}$ that included presence of at least two of the three following features; maternal age ( $\geq 40$ years), a previous POR $(\leq 3$ oocytes with a conventional stimulation protocol) and an abnormal ovarian reserve tests includingantral follicle count $(\mathrm{AFC})<5$ and Anti-Müllerian hormone (AMH) $<1.1 \mathrm{ng} / \mathrm{mL}$ and / or elevated FSH on days 2 or 3 of the menstrual cycle more than $10 \mathrm{IU} / \mathrm{L}$. All the included female had normal uterine cavity.

The exclusion criteria included body mass index $(\mathrm{BMI}) \geq 30 \mathrm{mg} / \mathrm{m}^{2}$, FSH $>20 \mathrm{IU} / \mathrm{L}$, endocrine or metabolic disorders, such as diabetes mellitus, thyroid disorders, and polycystic ovarian syndrome, severe endometriosis, abonormal gynecological bleeding of undetermined origin, allergy to the used medications, medical treatment with corticoids, azospermia or women with uterine malformation or abnormality.

The patients were randomized through a computergenerated randomization sequence into the three groups through using 90 sealed opaque envelopes. The patients were allocated in one of three groups (30 patients each):

Control group (HMG/GnRHant protocol) (30 patients): Women of this group received HMG/GnRH antagonist protocol.

GH group (GH/HMG/GnRHant protocol) (30 patients): Women of this group received GH/HMG/GnRH antagonist protocol. Patients received daily subcutaneous injection of $2.5 \mathrm{mg}$ of GH (equivalent to $7.5 \mathrm{IU}$ ) (Norditropin, Novo Nordisk) from day 21 of previous cycle, until the day of HCG injection.

DHEA group (DHEA/HMG/GnRHant protocol) (30 patients): Women of this group received
DHEA/HMG/GnRH antagonist protocol. Patients received $25 \mathrm{mg}$ of micronized DHEA, administered orally three times a day, for 12 weeks before starting the cycle of ovulation induction.

The participating females underwent full history taking, medical and gynecological examination. Transvaginalsonographic evaluation was done.

Treatment protocol:

Ovarian stimulation was started in all women in the three studied groups from the second day of menstrual cycle with 300 IU of HMG. Ovarian response monitoring was performed using serial vaginal ultrasonography and measuring serum E2 levels. When dominant follicles reached to $14 \mathrm{~mm}$ in mean diameter, $0.25 \mathrm{mg} /$ day of $\mathrm{GnRH}$ antagonist was started and continued to prevent premature luteinization until the day of HCG injection in both groups. When at least two follicles with a mean diameter of $17 \mathrm{~mm}$ were observed, 10,000 IU HCG was injected. Endometrial thickness and serum E2 levels were measured in the day of HCG injection. Oocyte retrieval was done 34-36 h after HCG injection using a 17-gauge needle under vaginal ultrasonography guidance, and conventional IVF or intracytoplasmic sperm injection (ICSI) was performed appropriately. Embryos were transferred using a labotect catheter (labotect, Gottingen, Germany) $48-72 \mathrm{~h}$ after oocytes retrieval. At most three embryos were transferred in each In vitro fertilization-Embryo transfer (IVF-ET) cycle and excess embryos were cryoprecipitated. Luteal phase support was started with progesterone in oil $100 \mathrm{mg}$ daily IM on the day of oocyte retrieval and continued until the documentation of fetal heart activity by ultrasound.

Quantitative $\beta$ HCG was performed 14 days following embryo transfer and was considered positive if $\geq 50 \mathrm{IU} / \mathrm{L}$. In cases with confirmed pregnancy, transvaginalsonographic was performed two weeks later to confirm the presence of an intrauterine sac with positive fetal pulsations. Pregnant cases were followed up till delivery. Primary outcomes were the number of oocytes retrieved and the clinical pregnancy rate. Secondary outcomes were the number of fertilized oocytes, number of embryos transferred and live birth rate (LBR).

Fertilization of oocytes was defined with observation of at least one pronucleus or cleaved oocytes. Implantation rate defined by the number of gestational sacs per transferred embryos was calculated. Cycle cancellation rate, chemical pregnancy rate, ongoing pregnancy rate and early miscarriage rate were calculated.

Cycle cancellation is identified when no embryo is transferred because of failed oocyte retrieval (no obtained oocyte on the day of ovarian puncture), or failed fertilization and/or cleavage (no obtained embryo after IVF/ICSI).Chemical pregnancy is defined as a serum beta $\mathrm{HCG} \geq 50 \mathrm{IU} / \mathrm{L}, 14$ days after embryos transfer. Clinical pregnancy is identified as observation of fetal heart activity by trans-vaginal ultrasonography performed 5 weeks 
after positive beta HCG. Ongoing pregnancy is defined as pregnancy proceeding beyond the 12th gestational week. Early miscarriage was defined as loss of pregnancy before 12 weeks of gestation. LBR was defined as the number of achieved live birth after 28 weeks of gestation.

\section{Statistical analysis}

Data were fed to the computer and analyzed using IBM SPSS software package version 20. (Armonk, NY: IBM Corp). The Kolmogorov-Smirnov test was used to verify the normality of distribution. Quantitative data were described using mean \pm standard deviation and were analyzed using one way ANOVA with Post Hoc Tukey test for pair wise comparisons. Qualitative data were described using number and percent. Comparison between categorical data was performed using Chi square test. Significance of the obtained results was judged at $\mathrm{P}<$ 0.05 .

\section{RESULTS}

A comparison between the three studied groups regarding demographic data including, age, BMI, duration of marriage and duration of infertility, and the basal levels of FSH, luteinizing hormone (LH), $\mathrm{E} 2, \mathrm{AFC}$ and $\mathrm{AMH}$ were insignificant different among the three groups $(\mathrm{P}>0.05)$. (Table 1$)$

\begin{tabular}{|l|c|c|c|c|}
\cline { 2 - 5 } \multicolumn{1}{c|}{} & Control group & DHEA group & GH group & P value \\
\hline Age (years) & $37.27 \pm 3.03$ & $38.6 \pm 2.91$ & $37.7 \pm 2.72$ & 0.199 \\
\hline BMI (Kg/m $\left.{ }^{2}\right)$ & $25.57 \pm 2.13$ & $26.20 \pm 2.47$ & $25.97 \pm 2.24$ & 0.556 \\
\hline $\begin{array}{l}\text { Duration of } \\
\text { marriage (years) }\end{array}$ & $9.0 \pm 2.79$ & $8.36 \pm 4.53$ & $9.93 \pm 3.77$ & 0.274 \\
\hline $\begin{array}{l}\text { Duration of } \\
\text { infertility (years) }\end{array}$ & $6.23 \pm 2.48$ & $6.5 \pm 4.28$ & $7.27 \pm 1.99$ & 0.407 \\
\hline AFC & $4.47 \pm 2.27$ & $4.77 \pm 2.18$ & $4.96 \pm 2.19$ & 0.679 \\
\hline AMH (ng/ml) & $0.85 \pm 0.77$ & $0.90 \pm 1.06$ & $0.89 \pm 0.82$ & 0.978 \\
\hline Basal E2 (pg/mL) & $116.77 \pm 49.64$ & $111.23 \pm 45.21$ & $108.43 \pm 49.32$ & 0.792 \\
\hline Basal FSH (IU/L) & $12.23 \pm 1.44$ & $12.73 \pm 1.85$ & $11.99 \pm 1.48$ & 0.191 \\
\hline Basal LH (IU/L) & $4.84 \pm 2.33$ & $4.68 \pm 2.54$ & $4.43 \pm 2.28$ & 0.797 \\
\hline
\end{tabular}

Data presented as mean \pm SD. Data presented as mean \pm SD.

Table 1:Basal patients' characteristics.

The mean values of the total dose of HMG (IU) and the duration of stimulation were statistically significant higher in the control group as compared to the DHEA and GH groups $(\mathrm{P}<0.05)$. They were lower in the DHEA group than the GH group $(\mathrm{P}<$ 0.05). A Comparison between the mean values of the number of the oocytes retrieved, MII oocytes, the

\begin{tabular}{|c|c|c|c|c|c|c|c|}
\hline & \multirow{2}{*}{$\begin{array}{l}\text { Control } \\
\text { group }\end{array}$} & \multirow{2}{*}{$\begin{array}{l}\text { DHEA } \\
\text { group }\end{array}$} & \multirow{2}{*}{$\begin{array}{c}\text { GH } \\
\text { Group }\end{array}$} & \multirow{2}{*}{$P$ value } & \multicolumn{3}{|c|}{ Post Hoc Test (Tukey) } \\
\hline & & & & & P1 & P2 & P3 \\
\hline Dose of HMG (IU) & $3830.0 \pm 514.71$ & $3050.0 \pm 394.57$ & $3340.0 \pm 470.94$ & $<0.001$ & $<0.001$ & $<0.001$ & 0.045 \\
\hline $\begin{array}{ll}\text { Duration } & \text { of } \\
\text { stimulation (days) }\end{array}$ & $12.77 \pm 1.72$ & $10.16 \pm 1.32$ & $11.13 \pm 1.57$ & $<0.001$ & $<0.001$ & $<0.001$ & 0.045 \\
\hline E2 on the HCG day & $929.73 \pm 387.36$ & $1760.0 \pm 683.72$ & $1678.17 \pm 743.97$ & $<0.001$ & $<0.001$ & $<0.001$ & 0.868 \\
\hline $\begin{array}{l}\text { Endometrial } \\
\text { thickness }(\mathrm{mm})\end{array}$ & $9.6 \pm 0.97$ & $10.17 \pm 1.29$ & $9.97 \pm 0.99$ & 0.133 & & & \\
\hline N oocyte collected & $4.2 \pm 1.94$ & $5.96 \pm 2.80$ & $4.5 \pm 2.03$ & 0.008 & 0.01 & 0.868 & 0.04 \\
\hline N MII oocyte & $2.63 \pm 1.33$ & $4.53 \pm 2.15$ & $3.2 \pm 1.4$ & $<0.001$ & $<0.001$ & 0.389 & 0.007 \\
\hline $\mathrm{N}$ fertilized oocyte & $1.80 \pm 0.99$ & $4.07 \pm 1.98$ & $2.77 \pm 1.55$ & $<0.001$ & $<0.001$ & 0.056 & 0.005 \\
\hline $\mathrm{N}$ transferred embryo & $1.57 \pm 0.86$ & $2.23 \pm 0.94$ & $1.67 \pm 0.8$ & 0.008 & 0.01 & 0.896 & 0.035 \\
\hline
\end{tabular}

Table 2:cycle characteristics. 
The cancelled cycle, the implantation rate and early miscarriage rate were statistically insignificant different among the three groups $(\mathrm{P}>0.05)$. The chemical pregnancy rate, clinical pregnancy rate, ongoing pregnancy rate and LBR per cycle start or per embryo transfer were statistically significant higher in the DHEA group compared to the control group and the $\mathrm{GH}$ group $(\mathrm{P}<0.05)$, while they were statistically insignificant different between the control and the GH group (P > 0.05). (Table 3, 4)

\begin{tabular}{|c|c|c|c|c|c|c|c|}
\hline & \multirow{2}{*}{$\begin{array}{l}\text { Control } \\
\text { group }\end{array}$} & \multirow{2}{*}{$\begin{array}{l}\text { DHEA } \\
\text { group }\end{array}$} & \multirow{2}{*}{$\begin{array}{c}\text { GH } \\
\text { group }\end{array}$} & \multirow{2}{*}{$\begin{array}{c}\mathbf{P} \\
\text { value }\end{array}$} & \multicolumn{3}{|c|}{ Post Hoc Test (Tukey) } \\
\hline & & & & & P1 & P2 & P3 \\
\hline Cancelled cycle & $5 / 30 ;(16.7 \%)$ & $3 / 30 ;(10 \%)$ & $4 / 30 ;(13.3 \%)$ & 0.749 & & & \\
\hline The fertilization rate & $62.5 \pm 34.03$ & $82.88 \pm 29.82$ & $78.39 \pm 34.42$ & 0.046 & 0.048 & 0.152 & 0.857 \\
\hline The implantation rate & $5 / 47 ;(10.6 \%)$ & $15 / 65 ;(23 \%)$ & $6 / 56 ;(10.7 \%)$ & 0.096 & & & \\
\hline $\begin{array}{l}\text { The chemical } \\
\text { pregnancy rate /cycle }\end{array}$ & $7 / 30 ;(23.3 \%)$ & $16 / 30 ;(53.3 \%)$ & $8 / 30 ;(26.7 \%)$ & 0.028 & 0.017 & 0.766 & 0.035 \\
\hline $\begin{array}{l}\text { The clinical pregnancy } \\
\text { rate/cycle }\end{array}$ & $3 / 30 ;(10 \%)$ & $12 / 30 ;(40 \%)$ & $5 / 30 ;(16.7 \%)$ & 0.014 & 0.007 & 0.448 & 0.045 \\
\hline $\begin{array}{l}\text { Ongoing pregnancy } \\
\text { rate/cycle }\end{array}$ & $2 / 30 ;(6.7 \%)$ & $10 / 30 ;(33.3 \%)$ & $3 / 30 ;(10 \%)$ & 0.011 & 0.01 & 0.64 & 0.028 \\
\hline $\begin{array}{ll}\text { Early } & \text { miscarriage } \\
\text { rate/cycle }\end{array}$ & $1 / 30 ;(3.3 \%)$ & $2 / 30 ;(6.7 \%)$ & $2 / 30 ;(6.7 \%)$ & 0.809 & & & \\
\hline LBR/cycle & $2 / 30 ;(6.7 \%)$ & $10 / 30 ;(33.3 \%)$ & $3 / 30 ;(10 \%)$ & 0.011 & 0.01 & 0.64 & 0.028 \\
\hline
\end{tabular}

Table 3:Reproductive outcomes.

\begin{tabular}{|c|c|c|c|c|c|c|c|}
\hline & \multirow{2}{*}{$\begin{array}{l}\text { Control } \\
\text { group }\end{array}$} & \multirow{2}{*}{$\begin{array}{l}\text { DHEA } \\
\text { group }\end{array}$} & \multirow{2}{*}{$\begin{array}{c}\text { GH } \\
\text { group }\end{array}$} & \multirow{2}{*}{$\begin{array}{c}P \\
\text { value }\end{array}$} & \multicolumn{3}{|c|}{ Post Hoc Test (Tukey) } \\
\hline & & & & & P1 & P2 & P3 \\
\hline $\begin{array}{l}\text { The chemical } \\
\text { pregnancy rate/ET }\end{array}$ & $7 / 25 ;(28 \%)$ & $16 / 27 ;(59.2 \%)$ & $8 / 26 ;(30.8 \%)$ & 0.037 & 0.023 & 0.828 & 0.037 \\
\hline $\begin{array}{l}\text { The clinical pregnancy } \\
\text { rate/ET }\end{array}$ & $3 / 25 ;(12 \%)$ & $12 / 27 ;(44.4 \%)$ & $5 / 26 ;(19.2 \%)$ & 0.018 & 0.01 & 0.478 & 0.049 \\
\hline $\begin{array}{l}\text { Ongoing pregnancy } \\
\text { rate/ET }\end{array}$ & $2 / 25 ;(8 \%)$ & $10 / 27 ;(37 \%)$ & $3 / 26 ;(11.5 \%)$ & 0.014 & 0.013 & 0.671 & 0.031 \\
\hline $\begin{array}{l}\text { Early miscarriage } \\
\text { rate/ET }\end{array}$ & $1 / 25 ;(4 \%)$ & $2 / 27 ;(7.4 \%)$ & $2 / 26 ;(7.7 \%)$ & 0.836 & & & \\
\hline LBR/ET & $2 / 25 ;(8 \%)$ & $10 / 27 ;(37 \%)$ & $3 / 26 ;(11.5 \%)$ & 0.014 & 0.013 & 0.671 & 0.031 \\
\hline
\end{tabular}

Table 4:Reproductive outcomes/ embryo transfer.

\section{DISCUSSION}

The results of the our study demonstrated that the number of retrieved oocytes, MII oocytes, fertilized oocytes, transferred embryo as well as the clinical pregnancy rate, ongoing pregnancy rate and LBR significantly improved in DHEA group as compared to the control and GH groups. However, no difference between the GH group and the control group was detected.

Up to our knowledge, there is no randomized controlled trial comparing the effects of administration of DHEA versus GH as adjuvant to the GnRH antagonists for the patients with POR.

The major mechanism of DHEA supplementation on the improvement of reproductive outcomes in POR patients may be explained by the increased androgen after DHEA supplementation. DHEA, a precursor of E2 and testosterone, serves as a prohormone of follicular fluid testosterone during ovarian induction. ${ }^{10}$ ARs have been identified in the granulosa cells at any follicular stage, especially preantral and antral follicles. ${ }^{11}$ Granulosa cell-specific androgen receptors are the crucial regulators of follicular development and fertility. In fact, androgen plays important roles in recruitment and initiation of primordial follicles, promotion of follicular growth through increasing FSH receptor expression, and prevention of follicular atresia by reducing apoptosis. $12,13,14$

Moreover, DHEA administration increases serum concentration of IGF- $1,{ }^{15}$ which has been reported to be correlated with oocyte quality and embryo development. ${ }^{16}$ Therefore, indirect action of DHEA was mainly presented. However, direct action of DHEA on the target organs has been proposed ${ }^{17}$ but is still inconclusive. Regarding the molecular mechanism, DHEA supplementation could improve mitochondrial function and reduce apoptosis in the $\mathrm{CC}$ and human GC line. ${ }^{18}$

Concerning the beneficial effects of adding the DHEA to the GnRH antagonists therapy for POR patients on the IVF outcomes, our findings were in concordance with the study carried out by Chern et al. ${ }^{19}$ They carried out a retrospective cohort study on 151 PORs fulfilled the Bologna criteria and underwent IVF cycles with the GnRH antagonist protocol and their patients allocated into two groups; the study group received $90 \mathrm{mg}$ of DHEA daily for 3 months before the IVF cycles and the control group underwent the IVF cycles without DHEA pretreatment. They found that the number and quality 
of retrieved oocytes, the number of transferable embryo, the clinical pregnancy rate, ongoing pregnancy rate and LBR were higher in the DHEA group than those measured in the control group.

Also, Kotb et al. ${ }^{20}$ compared the influence of administration of DHEA $25 \mathrm{mg}$ three times daily for 12 weeks before the IVF/ICSI cycles versus the control group that did not receive DHEA and they concluded that DHEA increases the number of oocytes, fertilization rate, and fertilized oocytes, in women with POR according to the Bologna criteria. The beneficial effect of DHEA supplementation on the IVF outcomes was documented in other studies.

In contrast to the results of our study regarding the effects of DHEA supplementation on IVF outcomes, including the clinical pregnancy rate, ongoing pregnancy rate and LBR, Kara et al. ${ }^{26}$ assessed the efficacy DHEA on IVF-ICSI outcome of poor responders in a RCT including 208 patients allocated into DHEA group and control group. They documented that the number of retrieved oocytes, MII oocytes, fertilized oocytes and transferred embryo, fertilization rate and pregnancy rates were not different between the groups. Also, Yeunget al. ${ }^{27}$ found no statistically significant differences in IVF outcomes in anticipated poor responders who received 12 weeks of DHEA supplementation before the start IVF treatment compared with placebo.

Regarding the effect of GH co-treatment to the IVF outcomes our results are in agreement with Eftekharet al. ${ }^{28}$ assessed IVF-ET cycle outcomes after the addition of $\mathrm{GH}$ in antagonist protocol in poor responders. Eighty-two poor responder patients selected for ART enrolled the study and were randomly divided into two groups. Group I $(\mathrm{GH} / \mathrm{HMG} / \mathrm{GnRHant}$ group, $\mathrm{n}=40)$ received $\mathrm{GH} /$ gonadotropin/GnRH antagonist protocol and group II (HMG/GnRHant group, $\mathrm{n}=42$ ) received gonadotropin/GnRH antagonist protocol. There were no significant differences between groups regarding the number and quality of retrieved oocytes, endometrial thickness, and the fertilization, implantation, and chemical and clinical pregnancy rates.

Moreover, Norman et al. ${ }^{29}$, Dakhly et al. ${ }^{30}$ and Bassiounyet al. ${ }^{31}$ investigated the impact of $\mathrm{GH}$ cotreatment to the IVF protocol poor responders. Their studies concluded that the use of GH co-treatment to the IVF had no significant difference in the number and quality of retrieved oocytes, chemical pregnancy, clinical pregnancy and LBR.

On the other hand Yovich and Stanger, ${ }^{32}$ reported that $\mathrm{GH}$ co-treatment to the IVF/ICSI treatment significantly improved the clinical pregnancy and LBR. Hazout et al. ${ }^{33}$ found that Co-stimulation with GH in a special population of patients with no clear explanation for their multiple failure of embryo transfer gave better results in terms of number of oocytes collected and embryos obtained. Pregnancy rate per retrieval was higher than in the control group.
We recommend further studies including a larger number of poor responders to define the place of DHEA supplementation in this challenging clinical situation, confirm the optimal dose and duration for DHEA supplementation. Further studies are recommended to investigate the effects of $\mathrm{GH}$ supplementation to the poor responders and to determine the appropriate dose, time of administration and even in which subgroup of patients GH should be used.

\section{CONCLUSION}

The DHEA supplementation to the IVF protocol improved the number and quality of retrieved oocytes, the number of transferable embryo, the rate of chemical and clinical pregnancy rate and the LBR compared to the control group or the $\mathrm{GH}$ co-treatment to the IVF protocol. However, the co-administration of the GH to the IVF protocol had no beneficial effects on the quality and number of the collected oocytes, the clinical pregnancy rate and LBR.

\section{REFERENCES}

1. Gleicher N, Weghofer A andBarad DH. Defining ovarian reserve to better understand ovarian aging. ReprodBiolEndocrinol, 2011; 9: 23.

2. Hyman JH, Margalioth EJ, Rabinowitz R, et al.DHEA supplementation may improve IVF outcome in poor responders: a proposed mechanism. Eur J ObstetGynecolReprodBiol, 2013; 168: 49-53.

3. Ferraretti AP, La marca A, Fauser BC, et al ESHRE consensus on the definition of "poor response' to ovarian stimulation for in vitro fertilization: the Bologna criteria. Hum Reprod, 2011; 26:1616-24.

4. Burger HG. Androgen production in women.FertilSteril, 2002; 77: S3-5.

5. Mamas L and Mamas E. Premature ovarian failure and dehydroepiandrosterone. FertilSteril, 2009; 91:644-6.

6. Casson PR, Lindsay MS, Pisarska MD, et al. Dehydroepiandrosterone supplementation augments ovarian stimulation in poor responders: a case series. Hum Reprod, 2000; 15(10):2129 32

7. Kucuk T, Kozinoglu H and Kaba A. Growth hormone co treatment within a GnRH agonist long protocol in patients with poor ovarian response: a prospective, randomized, clinical trial. J Assist Reprod Genet, 2008; 25:123-7.

8. Bachelot A, Monget $\mathrm{P}$, Imbert-Bollore $\mathrm{P}$, et al. Growth hormone is required for ovarian follicular growth. Endocrinology, 2002; 143: 4104-12. 
9. Weghofer A, Kim A, Barad DH, et al. The impact of androgen metabolism and FMR1 genotypes on pregnancy potential in women with dehydroepiandrosterone (DHEA) supplementation.Hum Reprod, 2012; 27: 328793.

10. Haning RV, Hackett RJ, Flood CA, et al. Plasma dehydroepiandrosterone sulfate serves as a prehormone for $48 \%$ of follicular fluid testosterone during treatment with menotropins. $J$ ClinEndocrinolMetab, 1993; 76(5):1301-7.

11. Slomczynska $M$ and Tabarowski Z. Localization of androgen receptor and cytochrome P450 aromatase in the follicle and corpus luteum of the porcine ovary. AnimReprodSci, 2001; 65(12):127-34.

12.Smith P, Steckler TL, Veiga-Lopez A, et al. Developmental programming: differential effects of prenatal testosterone and dihydrotestosterone on follicular recruitment, depletion of follicular reserve, and ovarian morphology in sheep. BiolReprod, 2009; 80(4):726-36.

13. Laird M, Thomson K, Fenwick M, et al. Androgen stimulates growth of mouse Preantral follicles in vitro: interaction with folliclestimulating hormone and with growth factors of the TGF beta superfamily. Endocrinology, 2017; 158(4):920-35.

14. Sen A, Prizant H, Light A, et al. Androgens regulate ovarian follicular development by increasing follicle stimulating hormone receptor and microRNA-125b expression. ProcNatlAcadSci USA, 2014; 111(8):3008-13.

15. Genazzani AD, Stomati M, Strucchi C, et al. Oral dehydroepiandrosterone supplementation modulates spontaneous and growth hormonereleasing hormone-induced growth hormone and insulin like growth factor-1 secretion in early and late postmenopausal women. FertilSteril, 2001; 76(2):241-8.

16. Fried G, Remaeus $\mathrm{K}$, Harlin J, et al. Inhibin B predicts oocyte number and the ratio IGFI/IGFBP-1 may indicate oocyte quality during ovarian hyperstimulation for in vitro fertilization. J Assist Reprod Genet, 2003; 20(5):167-76.

17.Alexaki VI, Charalampopoulos I, Panayotopoulou $\mathrm{M}$, et al. Dehydroepiandrosterone protects human keratinocytes against apoptosis through membrane binding sites. Exp Cell Res, 2009; 315(13):2275-83.

18. Tsui KH, Wang PH, Lin LT, et al. DHEA protects mitochondria against dual modes of apoptosis and necroptosis in human granulosa HO23 cells. Reproduction, 2017; 154(2):101-10.
19. Chern CU, Tsui KH, Vitale SG, et al. Dehydroepiandrosterone (DHEA) supplementation improves in vitro fertilization outcomes of poor ovarian responders, especially in women with low serum concentration of DHEA-S: a retrospective cohort study. ReprodBiolEndocrinol, 2018; 16(1):90.

20. Kotb MM, Hassan AM, and AwadAllah AM. Does dehydroepiandrosterone improve pregnancy rate in women 3 undergoing IVF/ICSI with expected poor ovarian response according 4 to the Bologna criteria? A randomized controlled trial. Eur J ObstetGynecolReprodBiol, 2016; 200:11-5.

21. Jirge PR, Chougule SM, Gavali VG, et al. Impact of dehydroepiandrosterone on clinical outcome in poor responders: A pilot study in women undergoing in vitro fertilization, using bologna criteria. J Hum ReprodSci, 2014; 7(3):175-80.

22. Barad D, Brill H, and Gleicher N. Update on the use of dehydroepiandrosterone supplementation among women with diminished ovarian function. J Assist Reprod Genet, 2007; 24:629- 34.

23. Wiser A, Gonen O, Ghetler Y, et al. Addition of dehydroepiandrosterone (DHEA) for poorresponder patients before and during IVF treatment improves the pregnancy rate: A randomized prospective study. Hum Reprod, 2010; 25(10):2496-500.

24. Singh N, Zangmo R, Kumar S, et al. A prospective study on role of dehydroepiandrosterone (DHEA) on improving the ovarian reserve markers in infertile patients with poor ovarian reserve.GynecolEndocrinol, 2013; 29(11):989-92.

25. Zangmo R, Singh N, Kumar S, et al. Role of dehydroepiandrosterone in improving oocyte and embryo quality in IVF cycles. Reprod Biomed Online, 2014; 28(6):743-7

26. Kara M, Aydin T, Aran T, et al. Does dehydroepiandrosterone supplementation really affect IVF-ICSI outcome in women with poor ovarian reserve?Eur J ObstetGynecolReprodBiol, 2014; 173:63-5.

27. Yeung TW, Chai J, Li RH, et al. A randomized, controlled, pilot trial onthe effect of dehydroepiandrosterone markers, ovarian response, and in vitro fertilization outcomes in poor responders. FertilSteril, 2014; 102(1):108115.

28. Eftekhar M, Aflatoonian A, Mohammadian F, et al. Adjuvant growth hormone therapy in antagonist protocol in poor responders undergoing assisted reproductive technology. Arch GynecolObstet, 2013; 287: 1017-21. 
29. Norman RJ, Alvino H, Hull LM, et al. Human growth hormone for poor responders: a randomisedplacebo controlled trial provides no evidence for improved outcome for live birth. Reprod Biomed Online, 2019; 38(6):908- 15.

30. Dakhly DM, Bassiouny YA, Bayoumi YA, et al. The addition of growth hormone adjuvant therapy to the long down regulation protocol in poor responders undergoing in vitro fertilization: Randomized control trial. Eur J ObstetGynecolReprodBiol, 2018; 228:161- 5.

31. Bassiouny YA, Dakhly DMR, Bayoumi YA, et al. Does the addition of growth hormone to the in vitro fertilization/intracytoplasmic sperm injection antagonist protocol improve outcomes in poor responders? Arandomized,controlled trial. FertilSteril, 2016; 105(3):697-702.

32. Yovich JL and Stanger JD. Growth hormone supplementation improves implantation and pregnancy productivity rates for poor-prognosis patients undertaking IVF. Reprod Biomed Online, 2010; 21: 37-49.

33. Hazout A, Junca A, Menezo Y, et al. Effect of growth hormone on oocyte competence in patients with multiple IVF failures. Reprod Biomed Online, 2009; 18:664-70. 